\title{
Observing the World from the Perspective of Multi-culture in Canada
}

\author{
Yue Yang \\ Guangzhou 510425, China \\ Tel: 86-135-4348-4054Ｅ-mail: yyllqq2007@163.com
}

\begin{abstract}
In the world, the relations of various cultures and civilizations are becoming fundamental in the human society of the era of globalization. The different relations within Canada are actually a microfilm of the worldwide cultural relations. The research on Canadian multicultural policy and reality can help us deeply understand the relations of various cultures in the world. Thus it is of global significance. This text, revolved around the multicultural issues, from Canadian and global angles, tries to give a brief description and exploration of such confusing phenomena and conceptions as the cultural unit, cultural conflict, cultural biological chain, cultural magic, cultural fog, cultural barriers, cultural trenches, Cultural Cold War, cultural background and cultural accumulation.
\end{abstract}

Keywords: Canada, Multi-culture, World culture, Global culture

Broadly speaking, cultural issues are the integrative problems dealing with political, economic, diplomatic, national, religious, educational and legal elements, community groups, civil customs, literature and art, press and public opinions, scientific research etc. "The cultural studies have become the most dynamic and creative academic trend of thought in the international academic community. And it is one of the most exciting fields in the contemporary intellectual life full of changes." (Cao and Zhang, 2005). "One of the most important features is the cultural diversity, which is determined by the different natural and social environments that human beings are in and the ways of thinking." (Laguna-carat, 2006, p.1). In the world, the relationships of various cultures and civilizations are becoming fundamental in the human society of the era of globalization.

"Canada is one of the countries with the most complex ethnic compositions. It is a leading country that advocates the cultural diversity. And its mosaic model is unique in the national cultures." ( Dai, 2007, p.9 ). Various cultural relations in Canada are a microfilm of the worldwide cultural relations. The research on Canadian multicultural policy and reality can help us deeply understand the relationships of global cultures, as is of global significance. To a certain extent, to solve the Canadian cultural problems can provide a useful inspiration to settle the world cultural or global cultural issues.

\section{Values and interests: cultural unit}

"The long world history tells us that the origin of human culture is diverse. In the world there has never existed a single global cultural pattern. The cultural diversity of human cultural sources still can be seen clearly so far. It can be said that the history of human civilization, in a sense, is the history of the development of cultural diversity of every nation." (Yu, 2007, pp. 206-207). The multi-culture contains a number of cultural subjects and every cultural subject is known as a cultural unit. There exist actual differences of various aspects in cultural subjects, that is, the cultural units. The differences are mainly in value orientation, interest ascription, the customs and styles. The value, interests and customs are the basic symbols to distinguish cultures. Each cultural unit has a particular value, specific interests and specific practices. Accordingly, every cultural unit is a community of people with common interests, common practices and common customs. The interests are especially attractive.

In human society, culture does not absolutely exist in isolation. Especially the ideological culture, which reflects the economy and politics, has generated and developed with their growth. Therefore, the fundamental reason leading to cultural conflict is the economic and political interests, including territory, wealth, resources, power, status, personal and group interests."(Zhao, 2004, p.123). A cultural unit is actually a value community, a community of interests and a custom community. The cultural identity of an individual is mainly the value of identity, interests and practices recognition. Only when an individual gets a cultural identity from a cultural unit, can he belong to that cultural unit. Although there are differences and contradictions of the members within a cultural unit, still the cultural unit displays the distinctive commonness of all members externally. If the ken of the commonness of the cultural unit can be expanded to the world, it would be a blessing to all the human beings.

\section{The Status quo and the situations: cultural conflict}

From the viewpoint of the process of social development, Canadian multi-culture has reflected more or less the 
historical progress. The most obvious is that violence is replaced by peace, duel by compromise, and conquest by coexistence. There is no doubt that the Canadian multi-culture has shown the goodwill of humanity, conscience and rational growth, as is commendable. However, the problem goes far beyond that. "There are complicated contradictions and differences between one theoretical policy and the reality. Since 1970s, multi-cultural policies and legislation of human rights have improved ethnic relations. But it does not mean that Canadian society has overcome and eliminated all the subjective and objective conditions resulting in the ethnic differences".( Gao, 1999, p.125). As far as the present is concerned, Canadian multi-culture has not harmonized fundamentally social contradictions, and basically eradicated social evils. From the situations of the international community, the same conclusion can be drawn. Mr. Huntington did not provoke deliberately but revealed truly the clash of civilizations. So far, it is still hard for people to strictly distinguish cultures from civilizations. If the concepts of the civilization and culture can be mixed up, the clash of civilizations also means cultural conflict. Furthermore, cultural conflict is undoubtedly the multi-cultural conflict. "In the contemporary world with increasingly obvious trend of globalization, culture has become an important factor to control the world pattern. The conflicts of cultural factors or caused by cultural factors do not only exist far and wide but also get severer and severer." (Zhao, 2004, p.120). The conflicts stem from the potential and complex advantages and disadvantages and hidden, complicated relations of multi-culture, which is testing the human beings dealing with complicated things rationally. If Multi-culture is a symbol of the era, then it is an era of glacis. The next step may be regressive, or stagnated, or progressive.

\section{Power and potential difference: cultural biological chain}

Every cultural unit in the pluralistic cultures is in different course of development and has weak or strong overall strength. Thus it has weak or strong power in the community. The difference of social power among all cultural units is equivalent to the difference in social status, as can be called potential difference. The dominant cultural units will certainly use this potential difference to give priority to their fellow members in the community while exclude the members of the other cultural units. The strongest cultural units will try its best to tyrannize over the stronger one and those in vulnerable situations, and keep the situation. The stronger cultural units, on the one hand, show their protest against being oppressed. On the other hand, they can get compensated by tyrannizing over the disadvantaged and exerts their efforts to keep obtaining the interests. The vulnerable cultural units are struggling to scrape their living in the cracks oppressed by the strong cultural units. The cultural units have formed a relationship of favoring the strong and excluding the weak. The sequent link among them is called the cultural biological chain. After long time of biological evolution, the human society which has stepped into the senior civilization drops to the low-level biological chain. It may be a mockery of embarrassment, a bitter irony, a big question mark for the civilization and culture the human beings are proud of.

\section{The ideal and the reality: cultural magic}

"The Canadian government has adopted the multi-cultural policy in order to ease the contradictions among the migrant nationalities, to support the migrants to develop their traditional national cultures and to protect their equal status in cultural and social life." (Dai and Wang, 2001, p.67). Canadian multi-cultural policy has depicted an ideal blueprint that all cultural units can co-exist harmoniously, treat and respect each other equally and friendly. However, due to the existence of the cultural biological chain and the cultural barriers, Canadian social reality is inconsistent with or deviates from the ideal blueprint of its multicultural policy. Whether to look up to the ideal blueprint in the situation of poor reality or to examine the poor reality from the ideal position, people will have to bear tremendous psychological and spiritual contrast. For such a phenomenon of contrast, an appropriate description is needed. It is certain that the multi-cultural policy is not a cultural shell game deliberately played by Canadian government. But to say the least, the multi-cultural policy can be compared to a cultural magic. As far as the multi-cultural policy at this stage is concerned, this scene of cultural magic seems to be tempting, attractive, worth appreciating and full of joviality. However, it is essentially not true. Political magic is prevalent in today's world. Every government is good at and keen on the performances of making wonderful commitments and slogans. The political magic, which is of duplicity and pleasing to both the eyes and the mind is very commonplace. Canada's cultural magic in nature belongs to a political magic. To meet the country's political demands, and serve the state politics, the Canadian cultural magic has played a role of whitewashing the peace, easing the tension and appeasing the people in the national governance. Any magic creates and utilizes the people's hallucinations. Cultural policy should be linked to reason, honesty and truth. It should be converted to scientific decision-making and social projects.

\section{Objectives and means: cultural fog}

Examining the Canadian multicultural policy and polishing it in legal documents, I think it tries to aim at putting forward an expected and ideal goal of development. Unluckily, it does not tell us clearly how to achieve the target. This phenomenon is like a mist or fog of culture that the people can not feel clearly within the sight. From the perspective of social progress, the right development goals are no doubt important. But it is also vital to make clear the way to achieve the goals. From the viewpoint of the problem of system engineering, it is more commendable to find the proper ways 
than to establish the correct target. The indistinct means of social development goals is like a mirage wonder. Better as it is, it is just a Utopia, which is of little significance to the progress of the human society in the modern world. A good desire and goal has always been cherished in the history. In today's world, what is needed most for human society is the actual action taken towards the right destination. Stressing the objectives, while ignoring the approaches, is not conductive to the Canadian multicultural policy to gain the good social benefits. It is necessary for the scholars studying the public policies and the officials formulating the public policies to spend more energy in finding the right approaches to realize the objectives of multicultural society and to remove the dense fog of culture before the people's eyes. Any nation, any country, or even the whole mankind is thirsty for a clear and bright cultural sky.

\section{Protection and exchanges: cultural barriers}

Based on the sacred dignity and the respect for nobleness, the protection of culture has become beliefs and tenets of unalterable principle. Therefore, the cultural protection weighs much in a multicultural policy. However, the cultural exchange has not got much attention. The orientation of the policy is one-sided. Thus, the social public has paid a one-sided attention to protecting the value and benefits of every cultural unit, in particular, to the self-protection. One-sided emphasis on the identity of the cultural values and interests within every cultural unit will virtually exclude the values and interests of other cultural units and the dissidents of the other cultures. Furthermore, cultural exchanges will be seriously impeded. The cultural policies and practices of one-sided protection, the exclusion of the dissidents, and impeding cultural exchanges are the cultural barriers. People are ready to undertake the roles of the defenders and fighters of cultural barriers. Both the social elite and the common people have surface knowledge of cultural exchanges. They can not give a clear definition and distinction of the concepts of cultural exchanges, cultural expansion, and cultural invasion in theory or in practice. Cultural exchanges suffer a lot while cultural expansion or cultural invasion is confidently opposed. The smooth cultural exchanges can not be easily and naturally achieved. There are a lot of difficulties to face and many risks to take. And expertise is also needed. Cross-cultural phenomenon has just aroused the attention of scholars. "When we use the term of cross-culture, we mean the communications happen among people of different cultural backgrounds. They may come from different countries, or just from the same country." (Sana and Deborah, 2004, p.7). Crossing cultural barriers is a challenge for cultural exchanges. (Bradford, 2003). However, whether in Canada or in the international community, people have not yet reached deep level and all-round realm of cultural exchanges. They are living in a world of cultural barriers full of mutual hostility, suspicion and precautions. Compared with the familiar trade barriers, the subtler cultural barriers are a hundred times more harmful to the advancement of human society.

\section{Division and integration: cultural trenches}

Cultural division is an important prerequisite of the cultural diversity. Culture, from different angles, can be divided into national or ethnic cultures, or various state cultures, or North American culture and South American culture, or European culture and Asian culture, or the Western culture and oriental culture, etc. Where there is a division, there is a boundary. Although the boundaries of culture are not clear in theory, in fact, they have become the cultural trenches. "All the peoples and states are used to living their lives and communicating each other within the border. They dare not and are unwilling to cross the border. They isolate themselves from the impact of the outside world."(Ostrom, 2003, p.40). Migrants can overstep the boundary of a country, but few can stride over the cultural trenches. There is no exception to the scholars, who are always standing on one side. Cultural exchange only stresses the apparent etiquette instead of the internal substantive. Confined by man's rational knowledge, decision-making, and behaviors in the current era, we can not see the situations of the current cultural integration, its trend and hope. And we have no way or dare not to predict its future. If cultural assimilation is impossible, separation will not be evitable. Not only in Canada, but also in other countries around the world, cultural trenches are replacing the boundaries of provinces, states and countries and have become the primary border of a large scale to polymerize the people. Since there is division, there exist inevitable distance. Between those people who are not in the same side of the cultural trench, and belong to different cultural communities, there exists a remote distance in emotion, understanding and communication. The scholars of comparative studies of culture have focused their interests on the uniqueness and differences of various cultural units. They have provided academic arguments for deepening the trenches and enlarging the gaps. In fact, the human culture has commonness. For example, truthfulness, benevolence, and beauty are the distillate advocated and pursued by a variety of cultures. The cultural commonness of human beings exists in all common cultures, as is the most original truth and valuable spiritual wealth. Comparative studies of culture should focus on finding the bilateral commonness of Sino-American culture, Britain-French culture, North and South American culture, Eurasian culture, and the Eastern-Western culture. As far as its importance is concerned, seeking common points speaks louder than reserving difference. The basic means of survival in the natural world and human society is to seek common points while reserving difference. Only by seeking common points, can differences be reserved.

\section{Identification and rejection: Cultural Cold War}

In the era of globalization, it is not oceans and borders but the multiple separatism and all kinds of cultural barriers and 
cultural trenches that seclude the people. Facing the multi-cultural barriers and trenches, people feel difficult to step over and they are always in embarrassment when conducting cross-cultural activities. First of all, they should pass the toll-gate of cultural identity. Cultural identity is the disguised form of cultural censoring. If you can not get your cultural identification, you are doomed to be refused culturally. The upgrading of the contradiction leads to the cultural exclusion and cultural discrimination. Cultural issues begin to have a political tendency. People are worrying about that. In a country or in the international community, culture has been reduced into a slave, bowing and scraping to the politics. Followed by the ideological Cold War from 1950s to the 1990s with features of class labels and ism camps, the human society has come into the swamp - a Cultural Cold War after getting rid of muddy quagmire. This is a round of new ideological cold war featured with cultural labels and cultural camps. From Szczecin by the Baltic Sea to Trieste beside the Adriatic Sea, the old Iron Curtain, used to traverse the European continent, has collapsed. In the global scope, lots of new iron curtains in the pluralistic separatist pattern have quietly come. To observe both sides of the new Iron Curtain, there are cultural fronts, cultural line of defense, cultural weapons in addition to cultural barriers and cultural trenches. There are cultural security, cultural attack and cultural threats besides cultural invasion. Witnessing such a state, any people who have sound reason except those who remain ignorant and apathetic would feel bitterly disappointed and disgusted. The next target of human society should be set to end the Cultural Cold War and to build a good and kind global village on the basis of reason and science. All will begin with just and modest cultural dialogues. Modesty and justice are the qualities that God adopts to inspire his people while pride and prejudice are the trap that Satan sets to confuse the people.

\section{Macrostructure and microstructure of society: cultural background}

The cultural unit is located at the macrostructure of society, while individuals are at the microstructure. Pluralistic cultures do not only reflect the relations among the cultural units at macrostructure but give impact on the personal life and destiny at microstructure. During the period of ideological Cold War, the society of the ideological extremism-the paramountcy of class and ism identification - stressed a person's class background and adopted the class stand and ism beliefs as a basic criteria to judge his identity. In such a society, people lived a depressive, restrained and terrible life. Unfortunately, the new ideological cold war, that is, the Cultural Cold War has followed it. Class and ism identification give their way to cultural identity. The supremacy of cultural identity becomes the mainstream of social ideology. A person's cultural background is valued, and cultural stand and the sense of cultural belonging are adopted to judge his identity as a basic criterion. In social life, class mark is replaced by the cultural mark. The cultural conflicts are in the place of class struggles. Immediately after the class label applied to every backbone was just torn off, the cultural label is affixed to the wounds. What the cold mainstream society recognizes is tags instead of identity. It is hard for those individuals who have no cultural identity to be accepted by the mainstream society. It seems what left for them is to be excluded or even abandoned by the mainstream society. Canadian skilled migrants of minority have been deeply troubled by their ethnic origin issues. A good case in point is that they have lived a bitter life, suffering from serious hidden discrimination and employment difficulties in this multi-cultural country. In any country, even in such a developed Western country as Canada of today's world, it seems there is a big gap between the real social conditions and the real human rights, freedom, equality and justice.

\section{Tradition and Innovation: cultural accumulation}

Multi-culture apparently has focused on each cultural unit of inheriting the cultural traditions respectively in case that it be lost and die out. As for innovation, it is not marked strikingly on the banner of cultural diversity. Therefore, from Canada to the other countries in the contemporary world, the human landscape is featured with cultural accumulation rather than cultural progress. This is a time when culture is wandering. This is a time when it is hard to tell good culture from bad one. Everyone knows that cultural traditions lasting for thousands of years have both essence and dross. But no one knows how to distinguish what on earth is the essence or what is the dross. On the one hand, a cultural tradition has very strong vitality. It can always regain its pneuma and get prosperous after a devastating revolutionary turmoil. On the other hand, the cultural innovation will meet many constraints and obstacles from the tradition. Facing with the profound cultural accumulation, what the scholars can do is to sing high praise of the good tradition or just avoid telling the correct and false of the tradition ambiguously. And what they do to the ancestors who cultivated the tradition is to awe and worship. Whether the tradition from the forefathers is good or bad seems to be a taboo question. By now no book of history and culture has been published on how to reserve the excellent practices or differentiate the corrupt customs with reason. The worse is that it has not become the generally accepted consensus. Such things occur to the culture of every nation, every country. It is the same to the world culture and global culture. When human beings can refine the culture rationally, when the disadvantages and advantages of cultural traditions are getting entirely distinct, a new era will begin.

\section{Conclusions}

Culture is one of the most popular concepts in the academia at home and abroad. (Wang. and Zhang, 2007, p.1) Cultural diversity is then getting known in the context of globalization. Pluralistic culture can be a policy tendency, or a doctrine, 
or a social ecology. However, it is not perfect or intact. The contemporary human living conditions in the cultural visual field can be summarized to be chaotic, unfair and peaceless.

Canada and the other parts of the world do need the harmonious multi-culture of seeking common points while reserving differences instead of the disintegrated one full of conflicts. However, the multi-culture that should have sought common points while reserving differences is to seek the common points while excluding, rejecting, even attacking the differences. The future progress of human society needs to seek common points among diverse cultures. The prospect and the ways to realize the multi-culture's seeking common points while reserving differences need further exploring. Shyness and regrets are needless for the human beings are objectively still in the state of the half-civilized and half-savage era. At this turning point of history, the age of enlightenment has not yet come to the end. Rationalism has not yet won its final success. The enlightenment needs to go on and the rational spirits still need to be carried forward. If we have much opener mind and wider visual span, we will see that the human civilization and human culture are the same sun rising from the horizon.

\section{References}

Cao, Weidong, \& Zhang, Guanghai. (2005). Culture and Civilization. Guilin: Guangxi Normal University Press.

Dai, Rong, \& Wang, Xiaoshan. (2001). Canadian culture. Beijing: Culture and Arts Publishing House. July, 2007. p.64.

Dai, Xiaodong. (2007). Canada: the cultural security in the context of globalization. Shanghai: Shanghai People's Publishing House. p.9.

Gao, Jianguo. (1999). Canadian culture and modernization. Shenyang: Liaohai Press. p.125

Hall, Bradford. J. (2003). Translated by Ma Zhengqi. Among Cultures: The Challenge of Communication. Beijing: Beijing Broadcasting Institute Press.

Laguna-carat, Anur. (2006). The cultural rights in the context of globalization. Beijing: China's media University Press. p.1.

Mora, Ostrom. (2003).Translated by Jia Zongyi. Crisis in globalization era? Beijing: Xinhua Publishing House. p.40.

Reynolds, Sana, \& Valentine, Deborah. (2004). Translated by Zhang Wei. Guide to cross-cultural communication. Beijing: Tsinghua University Press. p.7.

Wang, Xiaode, \& Zhang, Xiaomang. (2007). History and reality: studying the world's multi-culture. Tianjin: Tianjin People's Publishing House. p.1

Yu, Pei. (2007). Anti-cultural globalization-thinking about the cultural diversity in the context of economic globalization. In Yu Pei (Eds.), Globalization and global history. Beijing: Social Sciences Academic Press. pp. 206-207.

Zhao, Youtian. (2004). Competition of overall national strength and cultural conflicts. Changchun: Changchun Press. p.123. 